ISSN: $1130-3743$

DOI: http://dx.doi.org/10.14201/teoredu20152715367

\title{
SENTIDO CRÍTICO, GRAN POLÍTICA Y DEMOCRACIA MEDIÁTICA
}

\author{
Critical thinking, politics on a large scale and media \\ democracy
}

\section{Sens critique, grand politique et démocratie des médias}

José Antonio IBÁÑEZ-MARTÍN

Universidad Internacional de La Rioja. Vicerrectorado de Ordenación Docente y

Doctorado. Gran Vía del Rey Juan Carlos I, 41. 26002 Logroño, La Rioja.

jaimm@unir.net

Fecha de recepción: enero de 2015

Fecha de aceptación: abril de 2015

Biblid [(1130-3743) 27, 1-2015, 53-67]

\section{RESUMEN}

Un primer acercamiento a la realidad social actual nos ofrece numerosos motivos para la preocupación. El espectáculo de la violencia y de la inmoralidad puede fácilmente asustarnos. Pero más inquietante todavía es comprobar que el horizonte de convivencia, paz y bienestar que Europa había ido desarrollando desde el Tratado de Roma de 1957 se ha comprometido gravemente por la crisis económica. Hoy estamos ante un ataque a la política democrática, que se califica, por parte de la democracia mediática, como un sistema agotado, que exige ser cambiado por una nueva y gran política. El artículo analiza el concepto de gran política, acudiendo principalmente a Nietzsche, y señalando su unión con la gran filosofía y la gran educación. El estudio de los textos de Nietzsche nos lleva a la conclusión de cómo en ellos encontramos con frecuencia un interesante análisis de los problemas y una equivocada propuesta de soluciones. No cabe pensar en sugerir soluciones para todos los problemas planteados, pero sí se exponen diversas propuestas sobre los 
cambios del quehacer político que razonablemente se defienden desde la sociedad mediática. Como conclusión, se señala que la gran política exige estadistas capaces de defender modos de vida en común que puedan estructurar la convivencia a largo plazo.

Palabras clave: problemas contemporáneos; democracia en sociedad mediática; Nietzsche.

\section{SUMMARY}

The first approximation to the social current reality offers us numerous motives for the worry. The spectacle of violence and of immorality can scare us easily. But more worrying still it is to verify that the horizon of conviviality, peace and wellbeing that Europe had been developing from the Treaty of Rome of 1957 has compromised itself seriously for the economic crisis. Today we are before an assault to the democratic politics, which is qualified, on the part of the media democracy, as an exhausted system, which is required to be changed into a new and great politics, a politics on a large scale. The article analyses the concept of a politics on a large scale, primarily attending to Nietzsche, and noting its union with the great philosophy and the great education. The study of the texts of Nietzsche leads us to the conclusion of how in them we often find an interesting analysis of the problems and a misguided proposal for solutions. We cannot think to suggest solutions to all the problems, but we outline various proposals about changes of political activity, that reasonably are defended from the media democracy. In conclusion, we point out that a politics on a large scale requires statesmen, able to suggest modes of life in common that can structure a long-term coexistence.

Key-words: contemporary problems; politics in the media democracy; Nietzsche.

\section{SOMMAIRE}

Une première approche de la réalité sociale actuelle offre de nombreuses raisons de s'inquiéter. Le spectacle de la violence et l'immoralité peut facilement nous effrayer. Mais, plus inquiétant encore est de vérifier que l'horizon de coexistence, de paix et de bien-être qui avait mis au point l'Europe depuis le Traité de Rome de 1957 est sérieusement engagé par la crise économique. Aujourd'hui, nous avons une attaque sur la politique démocratique, qui a été qualifié, par la démocratie des media, comme un système épuisé, qui nécessite d'être changé par une nouvelle et grande politique. L'article analyse le concept de la grande politique, principalement selon Nietzsche et notant son union avec la grande philosophie et l'éducation grande. L'étude des textes de Nietzsche nous amène à la conclusion de la façon dont ils nous trouvent souvent une analyse intéressante des problèmes et une proposition erronée des solutions. Nous ne pouvons envisager ici de proposer des solutions à tous les problèmes, mais nous pouvons décrire diverses propositions sur les modifications de la vie politique que raisonnablement se défendent auprès de la société de médias. En 
conclusion, on a souligné que la grande politique exige des hommes d'État capables de défendre nouvelles modes de vie en commun qui peuvent structurer une coexistence à long terme.

Mots clés: problèmes contemporaines; politique et démocratie des medias; Nietzsche.

\section{INTRODUCCIÓN: ¿HAY MOTIVOS DE PREOCUPACIÓN ANTE LA SITUACIÓN POLÍTICA} ACTUAL? ${ }^{1}$

Se ha convertido en un lugar común la afirmación de que el filósofo tiene que comenzar el día leyendo el periódico, como si con ello se manifestara que no vive en una nube sino que está en contacto con la realidad vital.

Esta práctica, muy beneficiosa para la prensa escrita, que está pasando una grave crisis, hay que reconocer que mueve a la inquietud si no a la depresión. No entraremos en las noticias de la prensa amarilla, que acongojan el corazón cuando vemos padres que asesinan a sus hijos o madres que dejan morir al niño recién nacido, cuyo cadáver esconden en el frigorífico.

Pero hemos de reconocer que, aun dejando a un lado este tipo de noticias, el espectáculo nacional e internacional ofrece numerosos motivos para la preocupación. En efecto, son muchas las naciones hoy en día, en diversos continentes, que están en guerra, siendo continuos los asesinatos de gente inocente, a quienes se mata (a veces se los enjaula y se les quema vivos) por la religión que profesan o la etnia a la que pertenecen. Naturalmente una posición cómoda nos podría llevar a pensar que eso son problemas de civilizaciones poco desarrolladas, muy alejadas de nuestras circunstancias. Sin embargo, la realidad de nuestro país, así como la europea, se encuentra igualmente plagada de males gravísimos, al observarse numerosos casos de corrupción en políticos y empleados públicos de muy diversos países y tendencias ideológicas también muy distintas, así como conductas maritales de los representantes principales del Estado que parecen propias de un vodevil. No vamos a entrar en detalles, pero que se nombre secretario de Estado del Gobierno francés a una persona que llevaba años sin presentar la declaración sobre la renta y sin pagar el alquiler del lujoso piso en el que vivía, como ha ocurrido con Thomas Thévenoud, expresa el ambiente de inmoralidad en el que nos movemos, y explica la actitud de desprecio que hoy muchos ciudadanos tienen hacia la política, pues ven en ella la obsesión de poder, el engaño de unos programas que no se cumplen, la irresponsabilidad de unas decisiones que solo buscan conseguir votos, el alejamiento de los ciudadanos, los oscuros acuerdos con quienes reciben

1. Este artículo forma parte del proyecto "Promoción del aprendizaje ético-cívico en Internet. Política, familia y escuela", desarrollado por el Grupo de Investigación El quehacer educativo como acción, financiado por el Plan Propio de Investigación, Desarrollo e Innovación de la Universidad Internacional de La Rioja - Unir Research. 
dinero del Estado para obtener de ellos beneficios personales, etc., etc. Y hemos puesto sólo un ejemplo de Francia, pero podríamos seguir con un presidente de Gobierno de Italia, organizando bacanales con menores de edad, un ministro alemán copiando su tesis doctoral, un ministro inglés falsificando la declaración del conductor del coche multado, el director general del Fondo Monetario Internacional -con categoría de Jefe de Estado- atacando sexualmente a una limpiadora de hotel, todo ello por no hablar de lo que ha ocurrido en diversos lugares de España y con políticos de todos nuestros principales partidos políticos -como muy bien conocemos-, donde la corrupción económica ha alcanzado niveles inimaginables.

\section{LAS NOVEDADES DE LA SITUACIÓN POLÍTICA ACTUAL}

Al enfrentarse con estos hechos, algunos se limitan a decir que, en el fondo, ocurre lo que ha ocurrido siempre. Nadie es perfecto, afirman, y lo que pasa hoy es lo que ha pasado también en otros tiempos, con la doble particularidad de que antes eran pocos los que conocían lo que estaba pasando -mientras que hoy cualquier noticia llega al fin del mundo en pocos segundos- y que en la actualidad los ciudadanos no se resignan ante el mal con la misma facilidad con que se resignaban antes.

Ahora bien, la situación de nuestros días merece un análisis más profundo, pues mucho más inquietante que ese conjunto de inmoralidades citadas es la reaparición de problemas sociales que parecían superados y las propuestas de cambios estructurales sustanciales que pretenden transformar el horizonte que había ido construyendo Europa poco a poco, a partir de la Segunda Guerra Mundial y de la Declaración Universal de Derechos Humanos (DUDH). Efectivamente, el mundo occidental es quien con mayor empeño promueve la DUDH, con todo lo que ello lleva consigo del imperio de la ley sobre el absolutismo de cualquier Gobierno y de la promoción de las instituciones democráticas que puedan controlar la custodia de la dignidad humana y de sus derechos. Pero, a esto, Europa sumó el deseo de instaurar la política pertinente para impedir nuevas guerras entre las naciones europeas, y así creó una Comunidad Económica Europea, que se va desarrollando desde el Tratado de Roma de 1957 hasta el Tratado de Maastricht, 1993, que constituye la Unión Europea, alcanzándose entonces el objetivo deseado de la ciudadanía común a todos los europeos, la práctica eliminación de fronteras y el diseño de un sistema político caracterizado por la solidaridad, la tolerancia y la subsidiariedad, en la promoción de un Estado de bienestar, amparado por una acción política que, dentro del ámbito de la libertad de mercado, cuidaba el buen orden de la economía.

Sin embargo, veinte años después de la firma del Tratado de Roma, Europa, que parecía una isla de bienestar y pluralismo, entra en una fuerte crisis económica, que compromete seriamente lo que se creía que eran logros definitivamente adquiridos. La solidaridad, de repente, viene a ser cuestionada, primero porque se la describe como un error, cuyos efectos son favorecer a los vagos y no estimular 
al esfuerzo y, segundo, porque la disminución de oportunidades de empleo lleva a ver a las minorías como injustos competidores que pretenden quitar el pan de la boca a los que consideran que ese territorio les pertenece. El Estado de bienestar se ha visto obligado a recortarse, según unos, porque habría ido prometiendo más de lo que era posible repartir y, según otros, porque se ha quebrado la confianza de los ciudadanos en las instituciones financieras, en las bondades del libre mercado o en la disposición de los políticos por cuidar del buen orden de la economía (unos por defender mitologías desreguladoras y otros por preocuparse más de sus intereses que del bien común), mientras que otros insisten en que la crisis ha mostrado los límites intrínsecos de la democracia parlamentaria, a la que sería urgente sustituir por una nueva y gran política.

De este análisis que acabamos de presentar, es posible deducir que más importante que la denuncia de las inmoralidades o la lucha contra nacionalismos empequeñecedores, que agreden de diversas formas la cohesión social, es el ataque a la política democrática, descalificada por la llamada democracia mediática del momento como un sistema agotado, que debe ser abandonado de inmediato, a favor de esa gran política cuyos contornos no aparecen dibujados en lugar alguno con claridad.

Por ello, vamos a centrar nuestro estudio en reflexionar sobre el concepto de gran política, de modo que estudiemos sus fórmulas más reconocidas y evaluemos hasta qué punto son acertadas o de qué forma pueden ser reinterpretadas para ayudar a superar los problemas ante los que nos encontramos.

\section{LA GRAN POLÍTICA EN EL PENSAMIENTO CONTEMPORÁNEO}

No son muchos los autores que han usado esta terminología, que generalmente ha sido usada por algunos refiriéndose a la política exterior, como cuestión exclusiva de los soberanos absolutos, o a la política que busca los intereses del país por encima de otros sentimientos pequeños y, a veces, inconfesables.

Quizá el primer texto sobre el tema que aparece en un pensador político son unas cortas reflexiones de Gramsci tituladas Gran política y política pequeña, en los que hay diversas citas de personajes italianos, como Maquiavelo o Giolitti. Según estas reflexiones, la gran política

comprende las cuestiones vinculadas con la fundación de nuevos Estados, con la lucha para la destrucción, la defensa, la conservación de determinadas estructuras orgánicas económico-sociales. La pequeña política, por su parte, comprende las cuestiones parciales y cotidianas, que se plantean en el interior de una estructura ya establecida, debido a las luchas de preeminencia, entre las diversas facciones de una misma clase política (Gramsci, 1999, 18 bis-19).

Ahora bien, quien realmente pone sobre el tapete el tema de la gran politica es Nietzsche, que no tuvo reparo en afirmar que "sólo a partir de mí existe en la tierra la gran política" (Nietzsche, 2003a, 136), y no cabe la menor duda de que, sin pretender calificar a Nietzsche como la fuente intelectual del nazismo, sus ideas, 
muy frecuentemente contradictorias y de un alto nivel de ambigüedad, estuvieron claramente presentes entre quienes defendieron posiciones totalitarias, que se presentaban como planteamientos radicales para eliminar los errores del momento, usando una gran política que imprimiría rumbos enérgicos para hacer posible una nueva acción colectiva "que sabe manejar el cuchillo con seguridad" (Nietzsche, 2003 b, 210) y que movía a "conocer una nueva grandeza del hombre, un nuevo y no recorrido camino hacia su engrandecimiento" (Nietzsche, 2003b, 212).

De esta forma, rastreando entre los distintos escritos de Nietzsche, y siempre sin olvidar su tendencia a la paradoja - a la vez que es "un pensador radicalmente antidialéctico" (Moraleja, 2001, 18)-, que nos mueve a acercarnos más a los problemas que plantea que a las soluciones que defiende, nos encontramos con que la gran política está muy unida a la gran filosofía y a la gran educación, en un entramado complejo, discutible e interesante.

En efecto, una primera aproximación a la gran política la encontramos en su ya citada obra, Más allá del bien y del mal, cuando señala la necesidad de un cambio radical en Europa que consiguiera

mediante el instrumento de una nueva casta [...] adquirir una voluntad propia prolongada, terrible, que pudiera proponerse metas para milenios: para que por fin acabasen tanto la comedia, que ha durado demasiado, de su división en pequeños Estados como sus veleidades dinásticas y democráticas. El tiempo de la política pequeña ha pasado: ya el próximo siglo trae consigo la lucha por el dominio de la tierra, la coacción a hacer una política grande (Nietzsche, 2003b, 208).

Estas palabras pueden llevar a pensar que la pequeña política es la que estamos acostumbrados a ver, con las luchas entre las personas (antes, entre las dinastías, el juego de tronos) y sus intereses egoístas, mientras que la gran política buscaría el dominio de la tierra desde una nueva perspectiva cosmopolita, que superara las ridículas ambiciones de los déspotas pueblerinos. Pero, realmente, para Nietzsche, la gran política no está orientada tanto al dominio físico de la tierra cuanto a una nueva idea del hombre, una nueva visión de los valores que deben presidir su vida y su acción social. Ello significa que la gran política exige una nueva filosofía y una nueva educación, una gran filosofía y una gran educación.

Citar la gran filosofía me lleva a recordar un trabajo de Javier Gomá, en el que defiende "que la gran filosofía es ciencia del ideal: ideal del conocimiento exacto de la realidad, de sociedad justa, de belleza, de individuo" (Gomá, 2014, 108), que ofrece un "sentido unitario, intemporal, universal y normativo" (Gomá, 2014, 109), poniendo como ejemplo las propuestas de Platón; de Aristóteles -con el hombre prudente-; de Epicuro -el sabio feliz-; de Kant -el hombre autónomo-; de Nietzsche, el superhombre, etc. Mas esta gran filosofía hace décadas que ha desaparecido del horizonte cultural. Lo que hoy vemos en la vida universitaria, mantiene Gomá, es historia de la filosofía, críticas condenatorias de la modernidad en su conjunto o análisis de tendencias culturales que ofrecen interpretaciones de cómo somos en la actualidad. Todo ello podrá ser muy erudito e incluso lúcido, pero no es una 
"gran filosofía porque carece de intención propositiva, abarcadora y normativa, de una imagen del mundo completa y unitaria" (Gomá, 2014, 111).

Se ha dejado de hablar de la vida, sigue afirmando Nietzsche, para pasar a comentar los libros que hablaron de la vida. Se han congelado las fuerzas creadoras que elevan a lo mejor, para moverse en la crítica de los comportamientos de aquellos a quienes se les ha privado de un ideal por el que valga la pena esforzarse y luchar, a quienes se les ha convertido en un rebaño, cuya mayor ambición es "keep up with the Joneses".

Evidentemente, este capítulo del libro de Gomá muestra la condición diríamos profética de Nietzsche, pues una parte considerable de las críticas que Nietzsche dedica a la filosofía y a la educación de su tiempo son las que se señalan o se sugieren en dicha obra, como problemas presentes el día de hoy. En concreto, vamos a abordar tres puntos que considero que tienen una relevante actualidad, dejando a un lado los temas más conocidos de la filosofía de Nietzsche referentes a la construcción de la personalidad de los educandos, especialmente en su vertiente psicológica.

El primer punto trata sobre lo que Nietzsche llama, con un claro desprecio, el obrero filosófico, que nada tiene que ver con el auténtico filósofo. Transcribamos las siguientes palabras de nuestro autor:

Los obreros filosóficos, modelados según el noble patrón de Kant y de Hegel tienen que establecer y que reducir a fórmulas cualquier gran hecho efectivo de valoraciones -es decir, de anteriores posiciones de valor, creaciones de valor que llegaron a ser dominantes y que durante algún tiempo fueron llamadas "verdades"- bien en el reino de lo lógico, bien en el de lo político (moral), bien en el de lo artístico. A estos investigadores les incumbe el volver aprehensible, manejable, dominable con la mirada, dominable con el pensamiento todo lo que hasta ahora ha ocurrido y ha sido objeto de aprecio, el acortar todo lo largo, más aún, "el tiempo" mismo, y el sojuzgar el pasado entero: inmensa y maravillosa tarea de servir a la cual pueden sentirse satisfechos con seguridad todo orgullo sutil, toda voluntad tenaz.

No cabe duda de que el obrero filosófico tiene dimensiones valiosas. Puede decirse que:

tiene que haber sido tal vez crítico y escéptico y dogmático e historiador y, además, poeta y coleccionista y viajero y adivinador de enigmas y moralista y vidente y "espíritu libre" y casi todas las cosas, a fin de recorrer el círculo entero de los valores y los sentimientos de valor del hombre y a fin de poder mirar con muchos ojos y conciencias, desde la altura hacia toda lejanía, desde la profundidad hacia toda altura, desde el rincón hacia toda amplitud. Pero todas estas cosas son únicamente condiciones previas de su tarea: esta misma quiere algo distinto, exige que él cree valores (Nietzsche, 2003b, 211).

Aquí surge la idea, según Nietzsche, del auténtico filósofo: 
Estos son hombres que dan órdenes y legislan: dicen "jasí debe ser!», son ellos los que determinan el "hacia dónde" y el "para qué" del ser humano, disponiendo aquí del trabajo previo de todos los obreros filosóficos, de todos los sojuzgadores del pasado, ellos extienden su mano creadora hacia el futuro, y todo lo que es y ha sido conviértese para ellos en medio, en instrumento, en martillo. Su "conocer" es crear, su crear es legislar, su voluntad de verdad es voluntad de poder. ¿Existen hoy tales filósofos?, ¿Han existido ya tales filósofos? ¿No tienen que existir tales filósofos?... (Nietzsche, 2003b, 211).

No diría yo que tengan que existir esos filósofos, que confunden la voluntad de verdad con la voluntad de poder. Pero me parece muy digna de consideración la exigencia de no limitarse a ser un obrero filosófico (otras traducciones ponen trabajador filosófico), crítico y escéptico, incapaz de proporcionar una interpretación del sentido de la vida que permita convertir nuestra existencia en una aventura digna de ser vivida buscando una finalidad que realmente nos plenifique.

El segundo punto se refiere a la inmadurez que promueve la educación historicista y escéptica que se impartía entonces, según Nietzsche. Este tema se encuentra especialmente desarrollado en sus Consideraciones Intempestivas, titulada la segunda de ellas Sobre la utilidad y los inconvenientes de la Historia para la vida. No podemos desarrollar todos sus aspectos, pero la idea fundamental es que "necesitamos la historia para la vida y la acción, no para apartarnos cómodamente de la vida y la acción" (Nietzsche, 2006, 10). Al concluir esta Segunda Consideración Intempestiva, Nietzsche afirma que:

al investigar los peligros de la historia, nos hemos expuesto a todos esos peligros; nosotros mismos ostentamos las marcas de aquellos padecimientos que han sobrevenido a los seres humanos de la edad moderna a causa del exceso de historia. A su vez, el presente tratado refleja, no pretendo ocultármelo, su carácter moderno, es decir el carácter de una personalidad débil, en su crítica desmedida, en la inmadurez de su humanidad, en las frecuentes alternancias entre la ironía y el cinismo, entre el orgullo y el escepticismo. Y, no obstante, tengo fe, más que en el genio, en la fuerza inspiradora que guía mi barca, confío en la juventud y creo que me ha guiado bien al obligarme ahora a protestar contra el historicismo con que se pretende educar a la juventud de la humanidad moderna, y a exigir que el hombre aprenda, ante todo, a vivir y que recurra a la historia con el único propósito de ponerla al servicio de la vida aprendida (Nietzsche, 2006, 141-142).

Para Nietzsche es evidente que hay una forma de hacer historia que degenera, al estar alimentada por el escepticismo de una diversidad que ampara la vida egoísta y la acción vil y cobarde. Por ello, considera que lo esencial no está en recrearse en el conocimiento del pasado sino que es preciso

formar en vosotros una imagen del futuro y olvidad la creencia supersticiosa de ser meros epígonos. Tenéis suficiente que reflexionar e inventar en cuanto a la vida futura, pero no pidáis a la Historia que os indique el cómo y el con qué. Si, en cambio, penetráis en las vidas de los grandes hombres, de ellas aprenderéis el voto 
supremo mandamiento de madurar y escapar del encantamiento paralizante que emana de la educación de la época presente y que ve su utilidad en abstenerlos de madurar para dominar y explotaros por ser inmaduros (Nietzsche, 2006, 91-92).

Me parece muy acertado criticar a quien se dedica a saturar la mente de los jóvenes con multitud de datos que son incapaces de asimilar y, menos, de evaluar, y tanto más criticar a quienes hacen un uso de la historia que se limita a colaborar en la inmadurez de la juventud, pues fomentando la idea de que no pasamos de ser epígonos, de que les jeux sont faits, priva de fuerzas a los jóvenes para que realmente sean sujetos y dueños de su existencia, luchando por construir su futuro.

El tercer punto se refiere a la preocupación de Nietzsche por la defensa del desarrollo de la personalidad, que pienso que aparece en sus distintas obras bajo dos formas. La primera se encuentra en su publicación titulada Sobre el porvenir de nuestras escuelas (Primera conferencia), en donde afirma que:

en el momento actual, nuestras escuelas están dominadas por dos corrientes aparentemente contrarias, pero de acción igualmente destructiva, y cuyos resultados confluyen, en definitiva: por un lado, la tendencia a ampliar y a difundir lo más posible la cultura, y, por otro lado, la tendencia a restringir y a debilitar la misma cultura. Por diversas razones, la cultura debe extenderse al círculo más amplio posible: eso es lo que exige la primera tendencia. En cambio, la segunda exige a la propia cultura que abandone sus pretensiones más altas, más nobles y más sublimes, y se ponga al servicio de otra forma de vida cualquiera, por ejemplo, del Estado (Nietzsche, 1980, 58).

Esta idea tiene un expresión más fuerte en Más allá del bien y del mal. Allí leemos que «el gusto de la época y la virtud de la época debilitan y enflaquecen la voluntad, nada está tan en armonía con la época como la debilidad de la voluntad" (Nietzsche, 2003b, 212), terminando por mantener que: "en Europa es el animal de rebaño el único que recibe y que reparte honores, cuando la "igualdad de derechos" podría transformarse con demasiada facilidad en la igualdad en la injusticia" (Nietzsche, 2003b, 212).

Así, de manera majestuosa, escribe:

Yo quiero decir, combatiendo conjuntamente todo lo raro, extraño, privilegiado del hombre superior, del deber superior, de la responsabilidad superior, de la plenitud de poder y el dominio superiores; que hoy el ser aristócrata, el querer ser para sí, el poder ser distinto, el estar solo y el tener que vivir por sí mismo forman parte del concepto "grandeza"; y el filósofo delatará algo de su propio ideal cuando establezca: "El más grande será el que pueda ser el más solitario, el más oculto, el más divergente, el hombre más allá del bien y del mal, el señor de sus virtudes, el sobrado de voluntad; grandeza debe llamarse precisamente el poder ser tan múltiple como entero, tan amplio como pleno" (Nietzsche, 2003b, 212).

Volvemos de nuevo a encontrarnos en la paradoja, en la ambivalencia que caracteriza a las tesis de Nietzsche (Yacek, 2014, 393). No deja de ser cierto que se 
da hoy la tendencia no solo a ampliar sino, a la vez, a debilitar la cultura, es decir, a ver como sospechosa la búsqueda de la excelencia y a provocar una cultura de un igualitarismo que tiende a tratarnos como rebaño. Pero eso nada tiene que ver con creer que la grandeza se da en el más divergente, en el que se considera más allá del bien y del mal. Y, mucho menos, con el elitismo, igualmente contrario a la dignidad de toda persona, que pretende ver como errónea la necesaria tendencia a ampliar y difundir lo más posible los bienes de la cultura, ni con el autoritarismo que pretende que los grandes educadores puedan moldear, como artistas, al hombre mismo, según los dictados de su nueva visión de los valores, teniendo las "manos libres para poder utilizar en su cometido aquellos medios que estime más oportuno para llegar a su fin, tales como la coacción o el engaño" (Ginzo Fernández, 1999, 133).

Los textos de Nietzsche que hemos presentado muestran que cabe hablar de una gran filosofía, de una gran educación y de una gran política, pero a su vez manifiestan que el acierto en la identificación de los problemas no se traduce en un acierto en la propuesta de soluciones, y que esa grandeza puede ser mal interpretada, incluso desde el conjunto de la filosofía nietzscheana, pues no siempre vemos en él esa razón fuerte de la que en varios lugares nos habla.

Ahora bien, me parece que es un acierto subrayar la unidad de estos temas. Pienso que, efectivamente, no puede haber realmente una gran política si no está unida a una gran filosofía y a un gran proyecto educativo, y me parece que el principal mal de nuestros días es que se han roto los puentes para desarrollar esta unidad. Un proyecto más ambicioso debería llevarnos a analizar este conjunto de temas, pero los límites de un artículo me obligan a limitarme a hacer una propuesta de las características de la gran política, teniendo en cuenta tanto los motivos de preocupación del momento, de los que hablábamos al principio, como los problemas señalados por Nietzsche, que siguen plenamente vigentes, pero proponiendo soluciones propias, que no se encuentran en Nietzsche.

\section{Propuestas para una nueva política en la democracia mediática}

Ante las dificultades del momento, es fácil declarar que el sistema está agotado. Pero la realidad es que la democracia parlamentaria ha alcanzado cotas de libertad y desarrollo que no han sido capaces de conseguir otros sistemas y que no se ha hecho ninguna propuesta profunda que pueda considerarse como una alternativa. Por ello, no creo que el sistema democrático se encuentre agotado y haya de ser cambiado por otro distinto. Pero sí me parece que hay algunas nuevas exigencias que debieran tener en cuenta los políticos y los educadores.

\subsection{Principales cambios políticos exigidos por la sociedad mediática}

Concretamente me parece urgente, en la acción política de la sociedad mediática, introducir varios cambios significativos, entre los que señalaré cinco: 
a) La lucha contra la corrupción debe ser una meta básica en toda acción de gobierno. Es preciso tomar conciencia de que las diversas corrupciones de algunos políticos descalifican el trabajo de todos ellos y facilitan la desaparición del esfuerzo colectivo en la búsqueda del bien común. Naturalmente no se trata de luchar sólo contra los corruptos de otros partidos políticos: la primera obligación de un político es impedir la corrupción en el propio partido.

b) En una democracia se pide el voto a los ciudadanos para que opten por un programa de gobierno. Si los gobernantes no cumplen esos programas, no merecen que la confianza de los votantes se pueda volver a depositar sobre ellos, habiendo sembrado la idea de que, en el fondo, la política no pasa de ser una de las artes del engaño.

c) La democracia exige votar periódicamente a unos representantes. No tiene sentido pretender someter todas las decisiones de gobierno a continuas votaciones, cuando los ciudadanos ni tienen tiempo para ello ni formación técnica sobre muchos asuntos. Pero tampoco tiene sentido acallar la voz de los ciudadanos, como si en un partido la voz que únicamente debiera oírse fuera la de su jefe, o como si los órganos de gobierno debieran evitar toda participación ciudadana, cuando los nuevos medios de comunicación la facilitan.

d) Es importante educar en un ejercicio responsable de la política de Estado, enseñando desde la escuela que los gobernantes no deben vivir encerrados en los pequeños intereses locales ni entregados a la compra de votos usando el clientelismo político, sino que han de buscar el bien común, exigiendo a todos por igual el cumplimiento de las leyes.

e) Es urgente conseguir que todos los ciudadanos tomen conciencia de la importancia cívica de la responsabilidad y del respeto, independientemente del lugar que ocupen en la sociedad. Ya hemos citado la necesidad de la responsabilidad en el ejercicio de la acción política. Pero debemos subrayar que tal responsabilidad no recae solo sobre los gobernantes, sino que es compartida con los restantes ciudadanos, sean o no del partido en el poder, pues todos han de sentirse igualmente llamados a buscar el bien común, de forma que quienes no gobiernan han de huir del silencio ante el error del gobernante del propio partido, así como del enfrentamiento contra el gobernante por meras razones electorales, pues con ello se daña tanto la cohesión social como la imagen de las instituciones democráticas. Además, junto a la responsabilidad, debe promoverse siempre el respeto, tanto en quienes mandan en relación con quienes discrepan de sus decisiones, como en quienes mantienen criterios distintos a los defendidos por los que ejercen el poder, pues todos estamos llamados a evitar caer en el discurso del odio contra el oponente, lo cual, si siempre ha sido necesario, lo es más en la sociedad mediática pues "produce una considerable tristeza leer muchos comentarios que los periódicos publican como mensajes tras 
la mayor parte de las noticias. En efecto, lo más extendido es que escriban quienes parecen odiar a los demás, quienes sólo muestran amargura y resentimiento" (Ibáñez-Martín, 2013, 24). Es llamativo que la francesa Commissión Nationale Consultative des Droits de l'Homme haya publicado un Avis sur la lutte contre le discours de haine sur Internet, en cuya Recomendación n. ${ }^{\circ} 11$ pide "a los poderes públicos definir y llevar a la práctica una política represiva voluntarista contra los discursos de odio en Internet" (CNCDH, 2015, 28), lo que es una consecuencia de lo que ya se advertía hace unos años cuando un Report americano sobre los nuevos medios digitales señalaba el peligro de que «el espíritu cívico puede considerarse secundario si las libertades personales, como la libertad de expresión, son apreciadas a expensas de la comunidad" (James y otros, 2009, 74).

En pocas palabras, pienso que el eje de los cambios reposa sobre dos dimensiones fundamentales de la política, que necesitan replantearse, una sobre la figura del gobernante y otra sobre la actuación de los órganos de gobierno.

Sobre la figura del gobernante, de cualquier nivel, cada vez parece más urgente insistir en que debe caracterizarse por las siguientes notas:

a) Debe actuar con honestidad, sin que pueda ser objeto de reproche público por acciones ilegales o reconocidamente inmorales. La honestidad tiene un sistema de control, que es la transparencia económica de los partidos políticos, que deben dar cuenta del dinero que reciben y cómo lo gastan, así como tiene una base, que es conseguir que los gobernantes tengan los sueldos que son razonables, a la vista de sus responsabilidades. Es fácil que haya quienes se escandalicen ante un sueldo alto, pero querer disponer de gobernantes competentes pagándoles una parte pequeña de lo que ganarían en el sector privado es una pretensión más bien absurda.

b) Debe manifestar compromiso con el programa de gobierno por el que ha sido elegido y defenderlo personalmente en todas las instancias, esforzándose claramente por llevarlo a la práctica.

c) Debe tomar decisiones con una responsabilidad técnica razonablemente fundamentada. Evidentemente, confundir la acción política, que busca unos valores, con la tecnocracia es una equivocación, pero no hay peor defensa de unos valores que cuando se pretende llevarlos a la práctica sin disponer de una fundamentación racional y técnica suficiente.

d) Debe estar cercano a quienes representa, evitando posiciones de prepotencia. Un gobernante democrático nunca es un señor de horca y cuchillo, con derecho de pernada, sino un ciudadano capaz de escuchar a sus conciudadanos y de saber responderles razonadamente, sin entrar en polémicas descalificadoras.

Sobre la actuación y configuración de los órganos de gobierno, parece conveniente: 
a) Que las personas sean elegidas personalmente, es decir, que las listas sean abiertas, de modo que el ciudadano, dentro de un programa, pueda elegir a aquellos que le merecen más confianza. Los elegidos no pueden ser meros peones desresponsabilizados, sino que deben poder responder de sus decisiones a quienes les han votado, lo que lleva en Inglaterra a que no haya una lista única, sino que cada distrito elige una persona, que se sabe unida a un concreto conjunto de ciudadanos.

b) Que la participación ciudadana pueda ser habitual, a través de la organización de Foros deliberativos, donde se puedan exponer y discutir con los interesados las razones técnicas que avalan defender ciertas políticas, que se consideran más concordes con la idea del bien común expresada en el programa de gobierno aprobado. Evidentemente, un foro deliberativo delibera, no decide. Pero se intercambian ideas, se habla, se escucha, se ponderan razones.

c) Igualmente parece oportuno montar foros de opinión, donde los ciudadanos puedan expresar sus deseos sobre asuntos de interés común, ajenos al programa de gobierno y más cercanos a gustos que a razones técnicas: fiestas, adornos, mobiliario urbano...

Por la descripción que he ofrecido, se observa una diferencia en la estructura y el sentido de los foros señalado. En todo caso, los foros son instrumentos de diálogo, de participación y de propuestas. No son instrumentos decisorios, pues la democracia representativa nada tiene que ver con la asamblearia, que puede hoy presentarse como atractiva, pero que si se ha desechado con el tiempo no ha sido efecto de una conjura, sino consecuencia de una reflexión sobre lo que es mejor para el buen gobierno, y más en una sociedad mediática en la que ha aumentado el silencio de quienes piensan que su opinión va a ser criticada por quienes tienen mayor presencia en las redes sociales: basta observar la persecución implacable que se ha desatado contra Dolce y Gabbana para tomar conciencia de lo difícil que es defender las propias ideas cuando no son "políticamente correctas".

\subsection{Críticas y sentido crítico}

Acabamos de realizar unas propuestas que significan una crítica a la situación actual. Igualmente hemos señalado la condición profética de las algunas de las críticas emitidas por Nietzsche, de tal modo que no podríamos pretender buscar la promoción de una gran política si continuáramos atados a los errores que ya han sido denunciados.

Naturalmente, la crítica tiene que estar unida a un sentido crítico que nos lleve a ponderar el peso de las argumentaciones que descalifican ciertos comportamientos y el peso de las razones que quieren movernos a cambiarlos por otros distintos. El cultivo del sentido crítico siempre ha sido importante en el quehacer educativo, pero en estos momentos tiene especial urgencia cuando los peligros de 
manipulación social son mayores en la sociedad mediática. Más aun, actualmente está muy de moda atacar las instituciones democráticas sin ofrecer alternativa alguna, asegurando que todavía es pronto para proponerlas (lo que llevaría a una mera destrucción, no a un cambio) u ofreciendo presuntas soluciones -no solo en España sino también, aun distintas, en otros países europeos- que unas veces están basadas en políticas que ya manifestaron sus errores -como todavía se pueden comprobar en algunos países- y, en otras ocasiones, defendiendo planteamientos populistas, caracterizados por buscar la satisfacción de las masas ante una presunta solución de las angustias del momento, originando a la vez gravísimas dificultades para el futuro.

\title{
5. CONCLUSIÓN: EL POLÍTICO Y EL ESTADISTA
}

Como conclusión, diríamos que la gran política que cada vez necesitamos con mayor urgencia es la que llevan a cabo quienes merecen ser llamados realmente estadistas, que no son quienes hacen esa pequeña política, que limita su actividad a cuidar una recta organización de la economía, lo que no es nada despreciable ni secundario, sino quienes se esfuerzan en proponer, imaginativamente, unos modos de vida en común que puedan estructurar la convivencia a largo plazo, superando tanto los errores de la incompetencia, del clientelismo o de la corrupción, como el error de usar el poder autotélicamente para satisfacer la vanidad y la prepotencia, alejándose de los representados. Tenía mucha razón Maritain cuando poco antes de finalizar la Segunda Guerra Mundial decía, en unas famosas conferencias pronunciadas en Yale:

\begin{abstract}
Si no somos capaces de determinar en qué consisten la libertad, la justicia, el espíritu, la personalidad humana y la humana dignidad, y decir por qué estas cosas son dignas de que muramos por ellas, en tal caso no nos batimos y no morimos sino por vanas palabras. Si nosotros y la juventud que será educada por las futuras democracias creemos que todo lo que no es calculable o materialmente ejecutable es sólo un mito, y si solamente creemos en un mundo tecnocrático, en tal caso bien podremos vencer militar y técnicamente a la Alemania nazi, pero moralmente habremos sido derrotados por ella. Porque el prefacio o el comienzo del fascismo o del nazismo es el desconocimiento de la dignidad espiritual del hombre, y el postulado de que la vida y la moralidad humanas están reguladas por valores puramente materiales o biológicos (Maritain, 1950, 190).
\end{abstract}

Europa se ha caracterizado por proponer un mejor modo de cultivar el auténtico desarrollo humano, unido a una interpretación acerca de cuál es la verdad del ser humano sobre la que descansa su dignidad (cfr. Ibáñez-Martín, 2014). Si Europa olvidara su historia y pensara que es igualmente legítimo proponer cualquier tipo de organización de la vida en común, no se saldrá nunca de la crisis en que nos encontramos. 
El político se convierte en estadista, y de modo especial en una democracia mediática, cuando es capaz de proponer un amplio horizonte vital a sus ciudadanos, y cuando lo sabe presentar de un modo atractivo: la verdad sumada a la poesía termina consiguiendo ser escuchada aunque al principio encuentre rechazos. Siempre se recordará como estadista a quien al dedicar un cementerio de soldados proclamó solemnemente "que estos muertos no habrán muerto en vano; que esta nación, bajo la guía de Dios, vea renacer la libertad y que el gobierno del pueblo, por el pueblo y para el pueblo, no desaparezca de la faz de la tierra" (Lincoln, 1863), o a quien al dirigirse a su pueblo a los pocos meses de comenzar la Segunda Guerra Mundial afirmó "no tengo nada más que ofrecer que sangre, esfuerzo, lágrimas y sudor" (Churchill, 1940).

\section{REFERENCIAS BIBLIOGRÁFICAS}

Churchill, W. (1940) Discurso en la Cámara de los Comunes. May, 5.

Commission Nationale Consultative Des DRoits De l'homme (2015) Avis sur la lutte contre le discours de haine sur Internet. París.

Ginzo Fernández, A. (1999) Política, educación y filosofía, en F. Nietzsche, Revista de Estudios Políticos (Nueva Época), 104, abril-junio, 87-135.

Gomá, J. (2014) La deserción del ideal. ¿Dónde está hoy la Gran Filosofía?, en Razón: portería. Barcelona, Galaxia Gutemberg, 107-115.

Gramsci, A. (1999) Cuadernos de la cárcel, vol. 5. Edición crítica del Instituto Gramsci. A cargo de Valentino Gerratana. Puebla (México), Ediciones Era y Benemérita Universidad Autónoma de Puebla.

IbáÑez-Martín, J. A. (2013) Ética docente del siglo xxi: Nuevos desafíos. Edetania, 43, 17-31.

IBÁÑEZ-MARTín, J. A. (2014) Europa: la sabiduría y sus apariencias. La pedagogía del deseo y las disposiciones intelectuales. Revista Española de Pedagogia, 257, 77-92.

James, C. y otros (2009) Young People, Ethics and the New Digital Media: A Synthesis from the Good Play Project. Cambridge, Massachusetts, The MIT Press.

Lincoln, A. (1863) The Gettysburg Address. November, 19.

Maritain, J. (1950) La educación en este momento crucial. Buenos Aires, Dedebec.

Moraleja, A. (2001) Introducción. Nietzsche y la "gran política". Cuaderno Gris, tercera época, 5, 9-24.

Nietzsche, F. (1980) Sobre el porvenir de nuestras escuelas. Barcelona, Tusquets.

NieTzsche, F. (1994) Aurora. Madrid, M. E. Editores.

Nietzsche, F. (2000) Schopenhauer educador. Madrid, Biblioteca Nueva.

Nietzsche, F. (2003a) Por qué soy yo un destino, en Ecce Homo. Cómo se llega a ser lo que se es. Madrid, Alianza.

Nietzsche, F. (2003b) Más allá del bien y del mal. Madrid, Alianza.

Nietzsche, F. (2006) Sobre la utilidad y los inconvenientes de la historia para la vida. Buenos Aires, Libros del Zorzal.

YAсEK, D. W. (2014) Going to school with Friedrich Nietzsche: The Self in Service of Noble Culture. Studies in Philosophy and Education, 33, 391-411.

http://dx.doi.org/10.1007/s11217-013-9394-z 